\title{
Description of a new technique using biopsy forceps to stabilize pedunculated polyps for confocal laser endomicroscopy (with video)
}

The recently introduced technique of confocal laser endomicroscopy (CLE) enables in-vivo microscopic imaging of the mucosal layer of the gut at a subcellular resolution $[1,2]$. Several studies have shown that CLE has the potential to accurately discriminate between adenomatous and nonadenomatous colorectal polyps, and to enable the evaluation of the degree of dysplasia during ongoing endoscopy $[3,4]$. Nevertheless, in practice it is often difficult to receive confocal images of pedunculated polyps that are in focus because the polyps often "flap" away from the endoscope, which prevents stable contact between the confocal lens and the polyp tissue. We were confronted with this problem in a patient undergoing surveillance colonoscopy. A large, 15-mm, pedunculated polyp with Kudo pit pattern $3 \mathrm{~S}$ was visualized in the proximal sigmoid. Despite the size of the polyp, it was not possible to receive confocal images in focus because the polyp was repeatedly pushed away by the endoscope (Pentax EC-3870 CIFK, Tokyo, Japan). By grasping the head of the polyp with a standard biopsy forceps we could pull the polyp toward the confocal lens ( Video 1; $\bullet$ Fig. 1a-c) and receive high-quality confocal images on CLE of the polyp ( Video 1; $\bullet$ Fig. 1d). Although it is often difficult to perform CLE in pedunculated polyps we believe that the novel technique described here has the capability to considerably improve diagnostic outcomes.

\section{Competing interests: None}

\section{Endoscopy_UCTN_Code_TTT_1AQ_2AB}

\section{Video 1}

As shown in $\bullet$ Fig. 1, the head of the pedunculated polyp was grasped with standard biopsy forceps and pulled toward the confocal lens to receive confocal images in focus. Note the blue laser light at the 7 o'clock position.
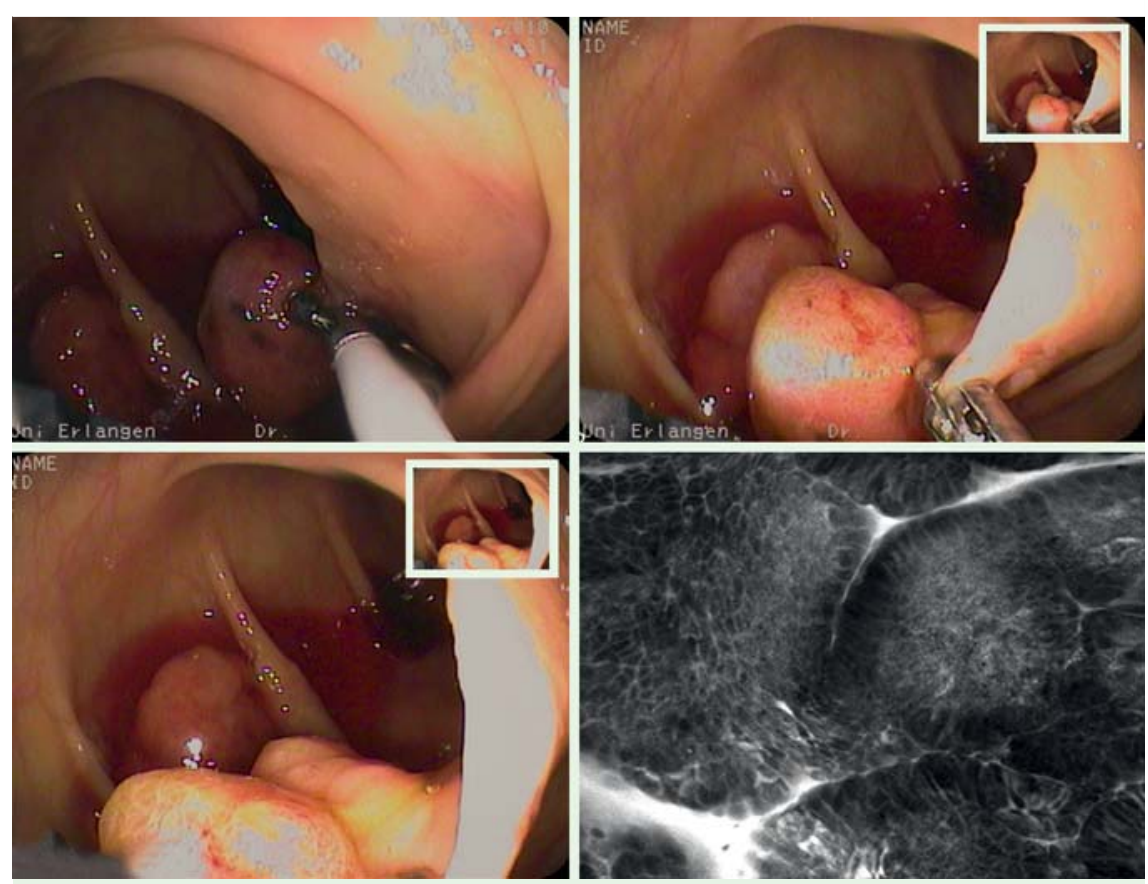

Fig. 1 a-d The head of the pedunculated polyp was grasped with standard biopsy forceps and pulled toward the confocal lens to receive confocal images in focus.

H. Neumann, M. Raithel, M. F. Neurath Department of Medicine I, University of Erlangen-Nuremberg, Germany

\section{References}

1 ASGE Technology Committee. Confocal laser endomicroscopy. Gastrointest Endosc 2009; 70: $197-200$

2 Goetz M, Kiesslich R. Advanced imaging of the gastrointestinal tract: research vs. clinical tools? Curr Opin Gastroenterol 2009; 25: $412-421$

3 Buchner AM, Shahid MW, Heckman MG et al. Comparison of probe-based confocal laser endomicroscopy with virtual chromoendoscopy for classification of colon polyps. Gastroenterology November 10 2009; [Epub ahead of print]

4 Sanduleanu S, Driessen A, Gomez-Garcia E et al. In vivo diagnosis and classification of colorectal neoplasia by chromoendoscopyguided confocal laser endomicroscopy. Clin Gastroenterol Hepatol August 13 2009; [Epub ahead of print]
Bibliography

Dol $10.1055 / \mathrm{s}-0029-1244005$

Endoscopy 2010; 42: E182

(c) Georg Thieme Verlag KG Stuttgart · New York . ISSN 0013-726X

\section{Corresponding author \\ H. Neumann MD, PhD}

Department of Medicine I

University of Erlangen-Nuremberg

Ulmenweg 18

91054 Erlangen

Germany

Tel.: +49-9131-85-35000

Fax: +49-9131-85-35209

helmut.neumann@uk-erlangen.de 